\title{
Case series of maternal mortality and maternal near miss due to severe acute respiratory syndrome coronavirus 2
}

\author{
Vanremmawii ${ }^{1}$, Lalrinfela ${ }^{2}$, Lalduhchhungi ${ }^{3}$, Harvey Vanlalpeka ${ }^{4}$, Lalramhluna PC ${ }^{5}$ \\ ${ }^{1,2}$ Associate Professor, ${ }^{3,4}$ Assistant Professor, ${ }^{5}$ Senior Resident, Department of Obstetrics and Gynaecology, Zoram
} Medical College, Falkawn, Mizoram, India

The severe acute respiratory syndrome coronavirus 2 (SARS-COV-2) that causes the COVID-19 pandemic has affected every household of the remotest part of North East India, Mizoram. The pregnant women do not have a higher chance of getting infected, yet the infection seems to be more severe. We are reporting five cases of maternal death and two cases of maternal near miss in ZMC of Mizoram. Case 1 to 5 were maternal death due to COVID-19. All of them were multigravida within the age group of 27-41 years with a period of gestation 24-37 weeks. The presenting complaints were fever and cough more than 3 days with an investigation report revealing raised $C$-reactive protein (CRP) and severe pneumonia. Case 6 (Near miss) was 20 years, primigravida at term pregnancy in labor with a history of fever for 2 days with an investigation report revealing raised CRP and severe pneumonia, the baby was delivered asphyxiated and died. Case 7 (Near miss) was 17 years old primigravida at term pregnancy admitted as asymptomatic COVID-19 positive, elective caesarean section was done for Obstetrics indication, the patient later developed fever and moderate pneumonia on 5 days of hospitalization, she also developed eclampsia on $7^{\text {th }}$ hospital day, she survived after intensive care in the intensive care unit.

Key words: SARS CoV2; Mamternal mortality; Near miss; Primi gravida
Access this article online

Website:

http://nepjol.info/index.php/AJMS

DOI: 10.3126/ajms.v13i1.39642

E-ISSN: 2091-0576

P-ISSN: $2467-9100$

Copyright (c) 2022 Asian Journal of Medical Sciences

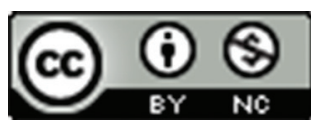

This work is licensed under a Creative Commons Attribution-NonCommercial 4.0 International License.

\section{INTRODUCTION}

The severe acute respiratory syndrome coronavirus 2 (SARS-COV-2), that causes COVID-19, since its discovery in Wuhan China in the month of December 2019 has percolated the remotest part of the world. The WHO has declared it as a Pandemic on January 2020. ${ }^{1}$ Globally the disease has affected 21.9 crore people all over the world with a death toll count of 45.5 lakhs recorded till date. This disease has been a cause of significant mortality even in the remote North Eastern State of India like our state Mizoram. The total number of cases in the state of Mizoram till date is 64672 with a total mortality of 226 people.

It was known that the COVID-19 infection is more severe in population with chronic illness such as Diabetes
Mellitus, Hypertension and Chronic Renal diseases, cardiovascular diseases, obesity, immune suppressed state and geriatric population Now it has been observed by various studies that covid 19 infection is more severe in pregnant women due to physiological changes of pregnancy. ${ }^{2,3}$ Since the first case of COVID-19 was admitted at Zoram Medical College (ZMC) in the month of March 2020, there have been 200 symptomatic cases of pregnant women admitted in the hospital with 5 number of maternal deaths.

This is the first study compiled and published from the North Eastern India on COVID-19 and pregnancy. The purpose of this study is to report on the 5 cases of maternal death and 2 cases of Maternal Near Miss. 


\section{PATIENTS AND METHODS}

\section{Study designs and participants}

This is a retrospective case series of maternal death and maternal near miss due to SARS-COV-2 admitted in ZMC Hospital.

\section{Case 1}

A 27 years old, Gravida 3 Parity 2 with 2 living issues, 36 weeks 5 days period of gestation (POG), with SARSCOV-2 positive by reverse transcription polymerase chain reaction (RT-PCR) was admitted on May 20, 2021 with a complaint of fever with chills and rigor, fatigue and cough for the past 3 days. On admission, she was fatigued, febrile, maintaining $\mathrm{Spo}_{2}$ of $95 \%$ at room air, Normotensive (120/70 mmhg), Pulse rate was $88 / \mathrm{min}$, her body mass index (BMI) was $26 \mathrm{~kg} / \mathrm{m}^{2}$. She had no history of systemic illness. Routine investigations were sent. She had mild iron deficiency anemia and significant lymphopenia and a reactive $\mathrm{C}$-reactive protein (CRP). Her liver function test (LFT) and Renal Function test were normal. Iron sucrose infusion was given on the $2^{\text {nd }}$ Hospital Day (HD). She developed shortness of breath on $3^{\text {rd }} \mathrm{HD}$, and her $\mathrm{Spo}_{2}$ dropped to $94 \%$ at room air. Contrast-enhanced computed tomography (CECT) chest was sent for after her saturation drops to $94 \%$ at room air, and she was diagnosed as severe pneumonia. Emergency lower segment cesarean section (LSCS) was done on the same day in view of maternal deterioration and desaturation. Three units of packed red blood cells (PRBC) were transfused on postoperative day 2. Her oxygen saturation was maintained at 95\% at room air but low-grade fever persisted and her saturation dropped to $85 \%$ on the $5^{\text {th }}$ postoperative day. It was then decided to give her Remdesivir as per National protocol along with low molecular weight heparin (LMWH) $40 \mathrm{mg} \mathrm{s} / \mathrm{c}$ once a day and injection dexamethasone $6 \mathrm{mg} 8 \mathrm{~h}$. She desaturated further, and was transferred to intensive care unit (ICU) on $8^{\text {th }} \mathrm{HD}$ and was put on Noninvasive ventilation (NIV). Her $\mathrm{SpO}_{2}$ was maintained at $98 \%$ with $\mathrm{FiO}_{2} 0.70$. She developed fever again on $10^{\text {th }} \mathrm{HD}$ and Arterial blood gas (ABG) analysis showed deterioration even on NIV at $\mathrm{FiO}_{2}$ 1.0. So endotracheal intubation was done and patient was put on Mechanical ventilation. Patient developed pneumothorax on $14^{\text {th }} \mathrm{HD}$ and Bilateral intercostal drain was inserted at $1 \mathrm{pm}$. However, the patient desaturated further and in spite of cardiovascular resuscitative measures, patient was declared dead at $7.30 \mathrm{pm}$ on June 4, 2021. In her family, her 2 children and her husband were also SARS-COV-2 positive, but they all recovered. Her total hospital stay was 15 days.

\section{Case 2}

Thirty years Gravida 3 parity 2 with 2 living issues, at 28 weeks POG was admitted with a chief complaint of fever, cough, and sore throat for 7 days on May 26, 2021 at $10.25 \mathrm{pm}$. She had no systemic illness. On admission, her $\mathrm{SpO}_{2}$ at room air was $90 \%$, heart rate $110 / \mathrm{min}$, Temperature $101^{\circ} \mathrm{F}$. She was weak and lethargic. Her BMI was 25. Oxygen inhalation was started with nonrebreather mask at $5 \mathrm{~L} / \mathrm{min}$ to maintain saturation at or above 95\%. Injection LMWH $40 \mathrm{mg} \mathrm{s} / \mathrm{c}$ once a day, inj. Dexamethasone $4 \mathrm{mg}$ iv TDS, and inj. Remdesivir as per protocol was started on admission. Investigations were sent for and showed significant lymphopenia, reactive CRP, normal kidney function test and LFT, her CECT chest showed severe pneumonia. She developed respiratory distress on $3^{\text {rd }} \mathrm{HD}$ and was shifted to ICU and endotracheal intubation was done immediately and patient was put on mechanical ventilation. On $4^{\text {th }} \mathrm{HD}$, her $\mathrm{SpO}_{2}$ was $92 \%$ with $\mathrm{FiO}_{2}$ at 1.0, blood pressure (BP) 120/78, CVP20 cmH2o, and positive end-expiratory pressure (PEEP) 10.

She had persistent fever and was given linezolid infusion, Ryles tube feeding, and other supportive treatment. She developed hypotension on $9^{\text {th }} \mathrm{HD}$ and noradrenaline and dopamine infusion was given. She developed surgical emphysema and bilateral implantable cardioverter defibrillator put on $10^{\text {th }} \mathrm{HD}$. Throughout her stay in ICU, fetal wellbeing was monitored by ultrasound, and fetus's condition was reassuring. Patient party was counseled regarding termination of pregnancy but consent was not given.

She continued desaturating and developed sudden bradycardia on $11^{\text {th }}$ HD and in spite of cardiopulmonary resuscitation, the patient was declared death at $8.10 \mathrm{pm}$ of June 6, 2021 (11 ${ }^{\text {th }}$ HD). Her total HDs was 11 days. Her sister-in-law who was 28 weeks pregnant was also infected with SARS-COV-2, but she was asymptomatic and fully recovered.

\section{Case 3}

A 35-year-old Staff nurse, Gravida 2 Parity 1 with one living issue, 37 weeks POG with a history of travel, and confirmed SARS-COV-2 by RT-PCR was admitted with body aches and sore throat on May 26, 2021. She was diagnosed as mild COVID-19 infection and put on supportive treatment. Her initial investigation showed normal lymphocyte count with severe iron deficiency anemia. She was given 3 units of PRBC on $4^{\text {th }} \mathrm{HD}$.

She developed fever with dysuria on $5^{\text {th }} \mathrm{HD}$, her temperature was $101^{\circ} \mathrm{F}$, Saturation was maintained at $96 \%$ at room air and fetal condition assessed by ultrasound was reassuring. She was put on injection Piperacillin and Tazobactam $4.5 \mathrm{~g}$ $8 \mathrm{~h}$, dexamethasone $6 \mathrm{mg}$ OD.

Her fever persisted over the next 4 days and $\mathrm{O}_{2}$ inhalation was given increasingly from $2 \mathrm{~L} / \mathrm{min}$ to $6 \mathrm{~L} / \mathrm{min}$ to 
maintain saturation at or above $95 \%$. Inj. Remdesivir was started on $9^{\text {th }}$ HD and CECT was sent for and diagnosed as severe pneumonia.

Emergency LSCS was done in view of maternal deterioration and a live male baby of $3 \mathrm{~kg}$ was delivered. Apgar score was good and baby later tested negative by RT-PCR. Patient was transferred to ICU postoperatively and put on NIV at $\mathrm{FiO}_{2} 0.70$ and LMWH started $12 \mathrm{~h}$ after operation. She was stable for the next 4 days but developed ARDS on the $6^{\text {th }}$ day of ICU admission, and was intubated and put on mechanical ventilation. She was stable and tolerated Ryles tube feeding for the next 3 days, but developed jaundice and fever on $3^{\text {rd }}$ day of mechanical ventilation. Ryles tube feeding was withheld and injection amoxiclav was started. ABG sent on the $5^{\text {th }}$ day of ICU (June 13,2021) showed respiratory acidosis. Intercostal drain bilateral was inserted June 13, 2021 to relieve pneumothorax. Despite maximum ventilatory support she continued desaturating and started deteriorated from June 15, 2021 and was declared death on 3.02 AM of June 17, 2021. Her total hospital stay was 22 days.

\section{Case 4}

Forty-one years old Gravida 3, Parity 2 Living issues 2, 24 weeks pregnant with no history of chronic illness, diagnosed as SARS-COV-2 by RT-PCR was admitted on June 22, 2021 at $6 \mathrm{pm}$. She complained of fever, cough, and fatigue for 3 days before her admission. On admission she was normotensive, temperature was $100^{\circ} \mathrm{F}$ with $\mathrm{SpO}_{2} 92 \%$ at room air. Her BMI was $24 \mathrm{~kg} / \mathrm{m}^{2}$. She was put on oxygen inhalation immediately with inj. LMWH and Dexona $6 \mathrm{mg} \mathrm{BD}$, and routine investigations were sent which were found to be within normal limit except $\mathrm{CRP}$ which was raised. Injection Remdesivir was started on the day of admission after getting LFT reports. On HD2, her SPO2 was $95 \%$ with $\mathrm{O}_{2}$ at $3 \mathrm{~L} / \mathrm{min}$, the CECT chest showed severe pneumonia and subsequently her oxygen requirement increase up to $14 \mathrm{~L} / \mathrm{min}$ on $3^{\text {rd }} \mathrm{HD}$. $\mathrm{ABG}$ was sent, diagnosed as respiratory acidosis and patient shifted to ICU and put on NIV, $\mathrm{SpO}_{2}$ was $99 \%$ with $\mathrm{FiO}_{2}$ at 1.0 and PEEP of 5. She was on ionotropic support from day 3 of ICU. She complained of shortness of breath on day 5 of ICU stay, her CRP was further raised, and injection Tocilizumab and inj. meropenem were started. On day $6^{\text {th }}$ of ICU admission, she complained of chest pain her respiratory rate was $45 / \mathrm{min}$, and $\mathrm{ABG}$ showed respiratory acidosis. She was then intubated and put on mechanical ventilation. There was no improvement clinically with maximum dose of double ionotropic support and maximal ventilatory support, and the patient steadily desaturated and was declared death on June 28, 2021 ( $7^{\text {th }}$ HD). Her total HD was 7 days only.

\section{Case 5}

Thirty-nine years old, 35 weeks POG Gravida 2 Para 1 Living issue 1 post cesarian section, reported to a District Hospital on July 10 at $8 \mathrm{pm}$ with shortness of breath, with a history of cough and fever for 1 week for which she had taken amoxycillin and cough syrup at home from the over-the-counter pharmacy. She had attended the Out Patient Department 2 days earlier for antenatal checkup and didn't give any history of cough or respiratory discomfort. RAgT was tested and found Negative on the day of examination. On examination, she was tachypneic, normotensive and $\mathrm{SpO}_{2}$ was $46 \%$. Oxygen inhalation was started immediately with mask and $\mathrm{SpO}_{2}$ was raised to $80 \%$ with $\mathrm{O}_{2}$ at $6 \mathrm{~L} / \mathrm{min}$. She was started on injection Amoxyclav $1.2 \mathrm{gm} \mathrm{BD}$, nebulization with combimist and budesonide. Oxygen inhalation was increased up to $10 \mathrm{~L} / \mathrm{min}$ in an effort to maintain $\mathrm{SpO}_{2}$ at $95 \%$. The next day, she desaturated even with $10 \mathrm{~L} / \mathrm{min}_{2} \mathrm{O}_{2}$ therapy and SARS-COV-2 test was repeated again by TrueNat and was found positive. He routine investigation showed significant lymphopenia She was referred to our hospital which was $250 \mathrm{~km}$ away and she developed acute respiratory distress syndrome on the way, and pulse and $\mathrm{BP}$ were not recordable on admission and CRP was done, but the patient was declared death on admission.

\section{Case 6}

Twenty years primigravida, 40 weeks pregnant with abdominal pain and a history of fever with Rigor and sore throat for 2 days, SARS-COV-2 positive by RT-PCR was admitted in early labour on December 09, 2020 midnight. She was febrile on admission, normotensive with $\mathrm{SpO}_{2}$ 95at room air. She delivered a girl of $3.5 \mathrm{~kg}$ at $5 \mathrm{AM}$ the next day. Baby was born asphyxiated and died $2 \mathrm{~h}$ later.

Her routine investigations were normal except CRP which was raised. She required $\mathrm{O}_{2}$ inhalation increasingly over the next 2 days, CECT chest on HD4 show severe pneumonia. she was then started on Remdesivir and injection Piperacilin, LMWH $40 \mathrm{mg}$ SC, Inj. methyl prednisolone $40 \mathrm{mg}$ BD the same day. Her saturation improved significantly and was oxygen-free by $8^{\text {th }} \mathrm{HD}$ and was fully recovered.

\section{Case 7}

Seventeen years old primigravida, Term pregnancy was admitted on May 28, 2021 after being tested COVID-19 positive by RT-PCR. On examination, she was afebrile, normotensive with $\mathrm{SpO}_{2} 98 \%$ at room air, term size uterus with reassuring fetal condition by ultrasound. El LSCS was done in view of unfavorable cervix with borderline Cephalopelvic Disproportion. A healthy live male baby of $4 \mathrm{~kg}$ was delivered with Apgar score of 9/10. Amniotic fluid and $48 \mathrm{~h}$ baby RT-PCR were negative for SARS-COV-2. The patient was well till the $5^{\text {th }} \mathrm{HD}$ when she developed fever 
and her $\mathrm{SpO}_{2}$ was $88 \%$ at Room air. CECT chest was done the same day which showed moderate pneumonia. She was immediately put on high flow oxygen inhalation and injection Remdesivir, injection Dexamethasone $4 \mathrm{mg}$ iv Bd and LMWH $40 \mathrm{mg}$ started. She developed eclampsia on $7^{\text {th }} \mathrm{HD}$ and was transferred to ICU, the seizure was controlled with inj Mgso4. She was on put on High flow non-rebreather mask oxygenation and saturation was maintained. She improved and became oxygen fee by $10^{\text {th }} \mathrm{HD}$ and discharged the next day.

\section{DISCUSSION}

To date, there is no study reporting on maternal death from COVID-19 in the North East India. The aim of this study is to report on the cases of maternal complications and death due to COVID-19 infection in our institute to have a better understanding of pathophysiology and clinical presentation and assessment of the illness. The possibility of sudden deterioration of apparently well pregnant women infected with SARS-COV-2 was noted. The mean age group in our series was 29.86 ranging from 17 to 41, similar to metaanalysis by Zaigham and Andersson ${ }^{4}$ on 108 pregnant women with symptomatic COVID-19 infection and that of Takemoto et al., ${ }^{5}$ who found a mean age of 31.5 (ranging between 20 and 43 years). The mean POG in this series was 34.4 weeks, and fever was the main complaint in all the cases. From this series, it appeared that fever in pregnant SARS COV2 is a precedent or indication of severe illness.

\section{Limitation of the study}

Our experience with SARS-COV-2 is still evolving and the management protocol changes day to day, and the number of cases is limited as this case series involved only the severe cases admitted since the pandemic started.

\section{CONCLUSION}

All the pregnant subjects in the study did not receive COVID vaccines (covishield/covaxin) as per the Ministry of Health and Family welfare guidelines during that time. Vaccination of the pregnant women as well as timely intervention of symptomatic pregnant women with available medicines may play a significant role in the outcome. The disease progression and pathogenesis of COVID-19 in pregnancy needs more research,in-depth analysis, and case-based reviews in future for better maternal and fetal outcome.

\section{REFERENCES}

1. World Health Organization. Corona Virus Disease Pandemic (COVID-19) Pandemic. Geneva: World Health Organization; 2019. Available from: https://www.who.int/emergencies/diseases/ novel-coronavirus-2019. [Last accessed on 2021 Nov 03].

2. Corman VM, Landt $\mathrm{O}$, Kaiser M, Molenkamp R, Meijer A, Chu DK, et al. Detection of 2019 novel Coronavirus (2019nCoV) by real-time RT-PCR. Euro Surveill. 2020;25(3):2000045. https://doi.org/10.2807/1560-7917.ES.2020.25.3.2000045

3. Mor G, Cardenas I, Abrahams V and Guller S. Inflamation and Pregnancy: The role of the immune system at the implantation site. Ann Acad Sci. 2011;1221(1):80-87. https://doi.org/10.1111/j.1749-6632.2010.05938.x

4. Zaigham $M$ and Andersson $O$. Maternal and perinatal outcomes with COVID-19: A systematic review of 108 pregnancies. Acta Obstet Gynecol Scand. 2020;99(7):823-829. https://doi.org/10.1111/aogs.13867

5. Takemoto ML, Menezes MO, Andreucci CB, NakamuraPereira M, Amorim MM, Katz L, et al. The tragedy of COVID-19 in Brazil: 124 maternal deaths and counting. Int J Gynaecol Obstet. 2020;151(1):154-156. https://doi.org/10.1002/ijgo.13300

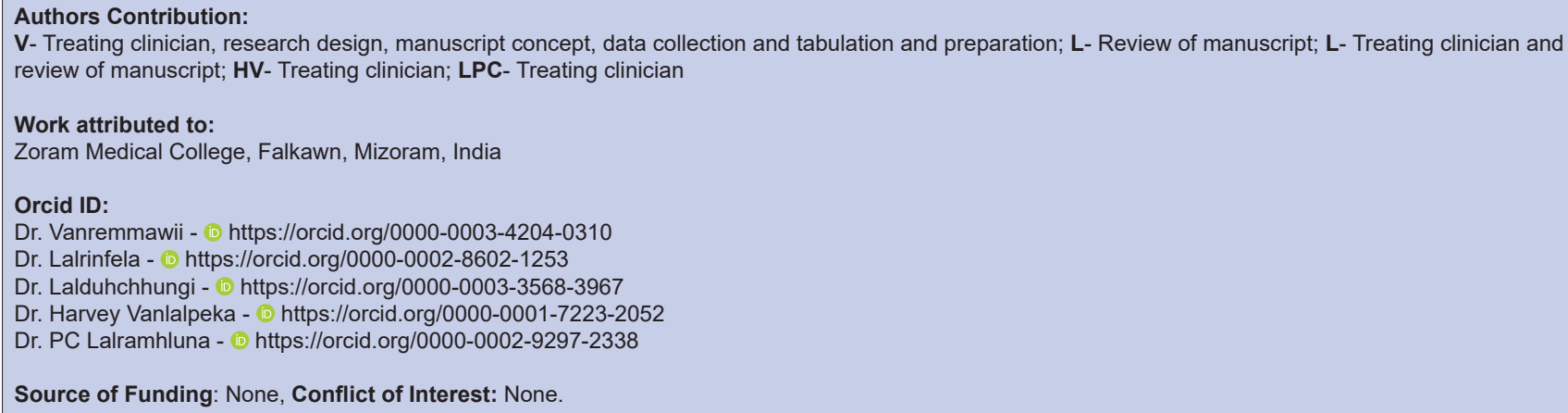

